\title{
Regulatory functions of self-restricted MHC class II allopeptide-specific Th2 clones in vivo
}

\author{
Ana Maria Waaga, ${ }^{1,2}$ Martin Gasser, ${ }^{1}$ Joana E. Kist-van Holthe, ${ }^{2}$ Nader Najafian, ${ }^{1}$ \\ Angelika Müller, ${ }^{1}$ John P. Vella, ${ }^{1}$ Karl L. Womer, ${ }^{1}$ Anil Chandraker, ${ }^{1}$ Samia J. Khoury, ${ }^{3}$ \\ and Mohamed H. Sayegh ${ }^{1,2}$
}

${ }^{1}$ Laboratory of Immunogenetics and Transplantation, Brigham and Women's Hospital, and
${ }^{2}$ Children's Hospital, Harvard Medical School, Boston, Massachusetts, USA
${ }^{3}$ Center for Neurologic Diseases, Brigham and Women's Hospital, Harvard Medical School, Boston, Massachusetts, USA

Address correspondence to: Mohamed H. Sayegh, Laboratory of Immunogenetics and Transplantation, Brigham and Women's Hospital, 75 Francis Street, Boston, Massachusetts 02115, USA.

Phone: (617) 732-5259; Fax: (617) 732-5254; E-mail: msayegh@rics.bwh.harvard.edu.

Received for publication September 27, 2000, and accepted in revised form January 30, 2001.

\begin{abstract}
We studied T-cell clones generated from grafts of rejecting and tolerant animals and investigated the regulatory function of Th2 clones in vitro and in vivo. To prevent allograft rejection, we treated LEW strain recipient rats of WF strain kidney grafts with CTLA4Ig to block CD28-B7 costimulation. We then isolated epitope-specific T-cell clones from the engrafted tissue, using a donor-derived immunodominant class II MHC allopeptide presented by recipient antigen-presenting cells. Acutely rejected tissue from untreated animals yielded self-restricted, allopeptide-specific T-cell clones that produced IFN- $\gamma$, whereas clones from tolerant animals produced IL-4 and IL-10. Adoptive transfer into naive recipients of Th1 clones, but not Th2 clones, induced alloantigen-specific delayed-type hypersensitivity (DTH) responses. In addition, Th 2 clones suppressed DTH responses mediated by Th1 clones in vivo and blocked Th1 cell proliferation and IFN- $\gamma$ production in vitro. A pilot human study showed that HLA-DR allopeptide-specific T-cell clones generated from patients with chronic rejection secrete Th1 cytokines, whereas those from patients with stable graft function produce Th2 cytokines in response to donor-specific HLA-DR allopeptides. We suggest that self-restricted alloantigen-specific $\mathrm{Th} 2$ clones may regulate the alloimmune responses and promote long-term allograft survival and tolerance.
\end{abstract}

J. Clin. Invest. 107:909-916 (2001).

\section{Introduction}

T-cell recognition of alloantigen is the key primary event that initiates allograft rejection (1). T cells recognize alloantigen via two distinct yet not mutually exclusive pathways $(2,3)$. In the direct pathway, $\mathrm{T}$ cells recognize intact allo-MHC molecules with an endogenous peptide on the surface of donor antigen-presenting cells (APCs). In the indirect pathway, T cells recognize donor-derived peptides presented by host APCs. $\mathrm{CD} 4^{+}$ $\mathrm{T}$ cells are the critical cells that orchestrate the whole cascade of graft destruction (4). Once fully activated by the T-cell-receptor-MHC-peptide (TCR-MHC-peptide) complex and costimulatory signals, $\mathrm{CD}^{+}$Th cells produce different cytokines which mediate various effector arms of the alloimmune response (2).

After antigenic stimulation, $\mathrm{CD} 4^{+} \mathrm{T}$ cells differentiate into two distinct populations, each producing its own set of cytokines and mediating separate effector functions (5). Th1 cells produce IL-2, TNF- $\beta$, and IFN- $\gamma$ and mediate cell immunity including delayed-type hypersensitivity (DTH) responses. Th2 cells produce IL-4, IL-5, IL-10, and IL-13, which provide help for B-cell function. These two cell populations have been shown to mutually regulate each other's function (6). Several studies in autoimmune and transplantation models show that tolerance induction, in particular by $\mathrm{T}$-cell costimulatory blockade, seems sometimes to be associated with a state of immune deviation towards predominantly Th2 cell function with inhibition of Th1 and upregulation of Th2 cytokines in the target organ (7-10). Therefore, it has been hypothesized that Th2 cells may function as regulatory cells in tolerant animals. In the murine autoimmune encephalomyelitis model, it has been demonstrated that Th2 clones generated from hyporesponsive animals can transfer tolerance to naive animals (11), providing evidence that Th2 cells can function as regulatory cells in vivo. Whether a Th2 switch regulates alloimmune responses remains controversial (12-14), since there are data indicating that animals that lack IL-4 can be tolerized (15) by T-cell costimulatory blockade. Therefore, the causality of an association between a state of immune deviation towards Th2 cell function and transplantation tolerance has not been proven.

We have previously demonstrated that self-restricted class II MHC allopeptide-specific Th1 cell clones from 
rats undergoing acute vascularized allograft rejection express a restricted TCR V $\beta$ repertoire and transfer DTH responses in vivo (16). In this study, we compared for the first time, to our knowledge, the functions of self-restricted alloreactive T-cell clones generated from grafts of rejecting and tolerant animals and analyzed the putative regulatory functions of Th2 clones in vitro and in vivo. Results of a pilot study in kidney transplant recipients with chronic rejection or stable graft function establish the biological relevance of our animal studies in humans. Our results confirm the regulatory functions of alloreactive Th2 clones and provide an invaluable tool for the study of the functions of Th1 and Th2 clones in acute/chronic allograft rejection and tolerance in vivo.

\section{Methods}

Animals. Inbred 200-250 g male Lewis (LEW; RT11) rats were used as recipients and Wistar Furth (WF; RT1 ${ }^{\mathrm{u}}$ ) rats served as donors. They were purchased from Harlan Sprague-Dawley Inc. (Indianapolis, Indiana, USA). Rat kidney transplantation. LEW rats underwent bilateral nephrectomies and received heterotopic MHCincompatible WF renal allografts. For the purpose of this study, we used two groups of animals. The first group was unmodified and the rejecting graft was harvested on day 7 . The second group was treated with a single injection of human cytotoxic lymphocyte activation factor 4 (CTLA4Ig; Bristol Myers Squibb Co., Princeton, New Jersey, USA) on day 2 after transplant and the graft was harvested after 100 days. This protocol of CTLA4Ig administration has previously been shown by Sayegh's group to induce long-term allograft survival with normal renal function and donor-specific tolerance in this model (7).

Patients. Renal allograft recipients who had received their transplants at least 6 months earlier and were attending the renal transplant clinic at the Brigham and Women's Hospital were screened. All patients were on triple therapy immunosuppression with cyclosporine, steroids, and azathioprine. Patients of specific interest had to be mismatched for one or more of the three candidate HLA-DR antigens for which synthetic peptides were available (DR1, DR2, and DR3). Two patients with biopsy-proven chronic allograft dysfunction with an elevated serum creatinine level $(\geq 2.0 \mathrm{mg} / \mathrm{dl})$ were compared with three patients with stable allograft function (stable serum creatinine $\leq 2.0 \mathrm{mg} / \mathrm{dl}$ ). The study was approved by the human subjects committee of the Brigham and Women's Hospital.

MHC allopeptides: The polymorphic RT1.B and RT1.D $\beta$ domains of RT1 ${ }^{\mathrm{u}}$ (WF) were selected and two peptides corresponding to residues 20-44 were synthesized commercially by Quality Control Biochemicals (Hopkington, Massachusetts, USA) as described (17). Both peptides have been published by our group as being immunogenic in vitro and in vivo; they induce a $\mathrm{T}$ cell-proliferative response in vitro and a DTH response in vivo after immunization of LEW animals (17). In addition, both peptides

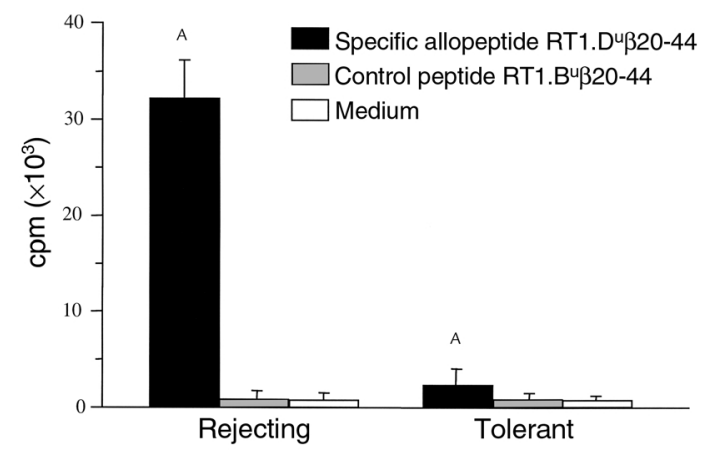

Figure 1

Proliferative responses of $\mathrm{T}$-cell lines from rejecting and tolerant animals to specific donor-derived MHC class II allopeptides. ${ }^{A} P<0.0001$ for proliferation in T-cell lines from rejecting versus tolerant animals. No significant proliferation over base line was observed against the nonspecific (control) allopeptide for both T-cell lines. Data are presented as mean $\pm \operatorname{SEM}(n=4$ experiments).

induce a proliferative response in $\mathrm{T}$ cells of animals rejecting WF-vascularized allografts $(18,19)$. More recently, we have shown that priming LEW recipients with the RT1.D ${ }^{u} 320-44$ peptide prior to transplantation accelerates the rejection process of vascularized WF cardiac allografts (20). Furthermore, a panel of peptides was synthesized corresponding to the full-length $\beta$-chain hypervariable regions of HLA-DRB1*0101, 1501, and 0301 (Chiron Mimotopes, Raleigh, North Carolina, USA), as previously reported (21). The peptides used for this study included the HLA-DRB*0101 (HLA-DR1 residues 42-62), HLA-DRB*1501 (HLA-DR2 residues 1-21 and 41-60), and HLA-DRB*0301 (HLA-DR3 residues 21-44).

Establishment of RT1.D" $\beta 20-44$ T-cell lines and clones. Lymphocytes were isolated from the transplanted kidney of rejecting (day 7) or tolerant (>100 days) LEW recipients of fully allogeneic WF renal allografts, as previously described (16). The cells $\left(4 \times 10^{6}\right)$ were then cultured with $50 \mu \mathrm{g} / \mathrm{ml}$ of RT1.D ${ }^{u} \beta 20-44$ peptide and both T-cell lines were incubated at $37^{\circ} \mathrm{C}$ with $5 \% \mathrm{CO}_{2}$ for 4 days. The cells $\left(2 \times 10^{5}\right)$ were repeatedly stimulated with the allopeptide at 7-day intervals in the presence of irradiated LEW splenocytes as APCs $(16,22)$. During the remaining period, the T-cell lines were cultured in complete medium with $10 \%$ IL-2 (Collaborative Biomedical, Bedford, Massachusetts, USA). T-cell clones were then generated from the RT1.D ${ }^{u} \beta 20$ $44-$ specific $\mathrm{T}$-cell lines by limiting dilution, as previously described $(16,22)$.

Establishment of HLA-DRB-specific T-cell lines and clones. PBLs were separated by Ficoll-Hypaque (Pharmacia Biotech, Piscataway, New Jersey, USA) density gradient centrifugation. The cells were then washed twice in RPMI 1640 medium (BioWhittaker Inc., Walkersville, Maryland, USA) containing 4\% normal human serum (Normalceraplus; North American Biologicals Inc., Miami, Florida, USA), $100 \mathrm{U} / \mathrm{ml}$ penicillin, $100 \mu \mathrm{g} / \mathrm{ml}$ streptomycin, $5 \mathrm{mM}$ HEPES, 1\% nonessential amino acids, and $1 \mathrm{mM}$ sodium pyruvate, and spun at $400 \mathrm{~g}$. The cells were 
Table 1

Characterization of rat T-cell clones generated from the kidneys of a rejecting and a tolerant animal

\begin{tabular}{|c|c|c|c|c|c|}
\hline \multirow[t]{2}{*}{ Clones } & \multicolumn{3}{|c|}{ Proliferation ${ }^{A}$} & \multirow[t]{2}{*}{ Phenotype $^{B}$} & \multirow[t]{2}{*}{ TCR V $\beta^{C}$} \\
\hline & Medium & RT1.D ${ }^{\mathrm{u}} \beta 20-44$ & RT1.B ${ }^{\prime \prime} \beta 20-44$ & & \\
\hline \multicolumn{6}{|c|}{ Rejecting } \\
\hline $2 \mathrm{~A} 2$ & $937 \pm 283$ & $34784 \pm 3326$ & $1543 \pm 258$ & $\mathrm{CD}^{+}{ }^{+}$ & 5.2 \\
\hline $2 \mathrm{~F} 7$ & $903 \pm 217$ & $33989 \pm 7968$ & $1560 \pm 273$ & $\mathrm{CD}^{+}$ & 8.1 \\
\hline 1F8 & $947 \pm 342$ & $38078 \pm 1898$ & $1628 \pm 168$ & $\mathrm{CD}^{+}{ }^{+}$ & 8.2 \\
\hline 2D5 & $895 \pm 297$ & $38975 \pm 5098$ & $1693 \pm 286$ & $\mathrm{CD}^{+}$ & 8.2 \\
\hline $1 \mathrm{G} 9$ & $964 \pm 385$ & $41593 \pm 4153$ & $1615 \pm 228$ & $\mathrm{CD}^{+}{ }^{+}$ & 9 \\
\hline \multicolumn{6}{|c|}{ Tolerant } \\
\hline $2 \mathrm{~F} 3$ & $809 \pm 306$ & $3329 \pm 827$ & $863 \pm 381$ & $\mathrm{CD}^{+}{ }^{+}$ & 3.3 \\
\hline $2 \mathrm{~F} 5$ & $877 \pm 312$ & $3448 \pm 943$ & $920 \pm 307$ & $\mathrm{CD}^{+}$ & 4 \\
\hline 1D2 & $936 \pm 239$ & $3831 \pm 1026$ & $983 \pm 493$ & $\mathrm{CD}^{+}$ & 8.2 \\
\hline $2 \mathrm{~B} 5$ & $847 \pm 437$ & $4240 \pm 749$ & $936 \pm 304$ & $\mathrm{CD}^{+}+$ & 9 \\
\hline $2 \mathrm{~A} 7$ & $908 \pm 396$ & $2979 \pm 583$ & $1003 \pm 295$ & $\mathrm{CD}^{+}$ & 13 \\
\hline
\end{tabular}

${ }^{A}$ CPm \pm SEM. ${ }^{B}$ Phenotype as determined by flow cytometry. ${ }^{C T C R ~ V ~} \beta$ determined by RT-PCR.
Flow cytometry analysis. T-cell clones were incubated with mouse anti-ratCD4 (W3/25; Harlan Bioproducts for Science Inc., Indianapolis, Indiana, USA) or anti-CD8 (MRC OX8; Harlan Bioproducts for Science Inc.) mAb's at a dilution of 1:100, as previously described $(16,22)$. The human T-cell clones were stained with conjugated FITC-anti-human CD4 and FITC-antihuman CD8 mAb's (BD PharMingen, San Diego, California, USA). The samples were analyzed by flow cytometry on a Becton Dickinson FACsort (Becton Dickinson Immunocytometry Systems, Mountain View, California, USA).

RT-PCR for TCR V $\beta$ expression. Total RNA was extracted from the cells $\left(5 \times 10^{6}\right)$ using the RNase total kit (QIAGEN Inc.,

finally counted after resuspension in RPMI medium that was the same as above except containing $10 \%$ normal human serum. PBLs from human renal allograft recipients $\left(4 \times 10^{6}\right)$ were cultured separately with $2.5 \mu \mathrm{g}$ of the mismatched donor-derived HLA-DR allopeptides. T-cell clones were generated by limiting dilution from the allopeptide-specific T-cell lines after three cycles of stimulation, as described for the rat clones above.

Proliferation assay. After generation of the T-cell lines and clones, $2.5 \times 10^{4}$ cells were cultured with $10 \mu \mathrm{g}$ (this dose was selected based on our previous publication showing the dose response curve for Th clones' proliferative responses to this peptide [ref. 16]) of the relevant allopeptide in 96-well U-bottom plates (Corning-Costar Corp., Cambridge, Massachusetts, USA) containing RPMI 1640 medium (BioWhittaker Inc.), 10\% FCS (for the rat cell lines and clones) or pooled normal human serum (for human cell lines and clones), $100 \mathrm{U} / \mathrm{ml}$ penicillin, $100 \mathrm{mg} / \mathrm{ml}$ streptomycin, $2 \times 10^{-5} \mathrm{M} 2$-mercaptoethanol and $5 \mathrm{mM}$ HEPES in the presence of irradiated self antigen-presenting cells $\left(1 \times 10^{5}\right)$. Proliferation was measured by ${ }^{3}[\mathrm{H}]$-thymidine (New England Nuclear Dupont, Boston, Massachusetts, USA) incorporation. All assays were set up in quadruplicates, and the results expressed as $\mathrm{cpm} \pm \mathrm{SEM}$.

ELISA for rat and human IFN- $\gamma$, IL-2, IL-4, IL-10, and TGF- $\beta$. T-cell lines and clones $\left(2.5 \times 10^{4}\right)$ were cultured in 96-well U-bottom plates (Corning-Costar Corp.) with $10 \mu \mathrm{g}$ of the relevant peptide as above. Negative control wells were set up with culture medium only. The plates were incubated at $37^{\circ} \mathrm{C}$ with $5 \% \mathrm{CO}_{2}$ for 48 hours or 72 hours, at which time point culture supernatants were taken for determining IFN- $\gamma$, IL-2, IL-4, IL-10 (48 hours), and TGF- $\beta$ (72 hours) production. Culture supernatants were assayed by ELISA using BioSource Cytoscreen Rat and Human ELISA Kits (BioSource International, Camarillo, California, USA).
Valencia, California, USA) and cDNA was prepared using the SuperScript Preamplification System for First Strand cDNA Synthesis kit using Random Primers (Life Technologies Inc., Gaithersburg, Maryland, USA). PCR amplification with the GAPDH housekeeping gene was performed to assess variations in total cDNA concentration between samples. RT-PCR was performed to compare the expression of TCR V $\beta$ repertoire in naive spleens, T-cell lines, and clones using $5^{\prime}$ primers specific for each of the 22 rat TCR V $\beta$ and for each of the 24 human TCR V $\beta$ and a 3' primer RTC $\beta .1$ from the TCR $C \beta$ region (16). Nonoverlapping oligonucleotide primer pairs were obtained by Genosys Biotechnologies (The Woodlands, Texas, USA). Reaction conditions included $1.25 \mu \mathrm{ldDNA}, 1 \mu \mathrm{M}$ of each $5^{\prime}$ and $3^{\prime}$ primers, $10 \mathrm{mM}$ Tris-HCl, $50 \mathrm{nM} \mathrm{KCl}, 1.5 \mathrm{mM} \mathrm{MgCl}_{2}, 0.001 \%$ (wt/vol) gelatin, $800 \mu \mathrm{M}$ dNTPs, and 0.625 units AmpliTaq DNA polymerase (Perkin-Elmer Applied Biosystems, Foster City, California, USA) in a total volume of $25 \mu$. The amplifications were performed in a thermocycler (Gene Amp. PCR System 9600, Perkin-Elmer Applied Biosys-
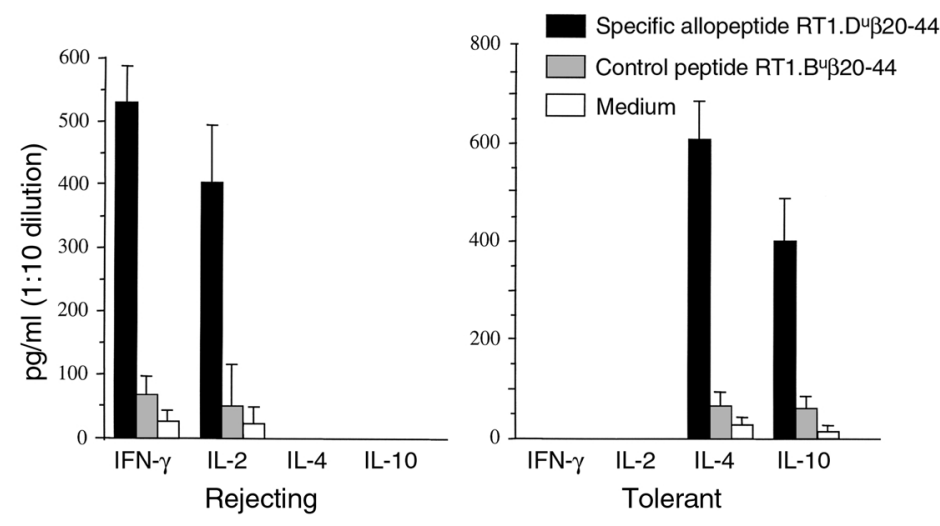

Figure 2

T-cell lines cytokine profile of rejecting and tolerant animals after restimulation with the RT1.D $\mathrm{u} \beta 20-44$ allopeptide. Data are presented as mean \pm SEM ( $n=4$ experiments). 

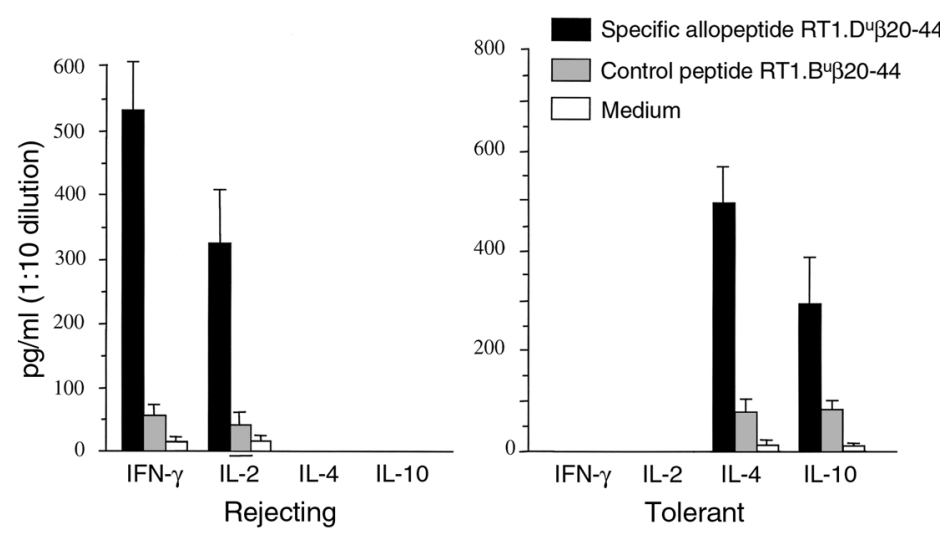

Figure 3

T-cell clone cytokine profile patterns of rejecting and tolerant animals after restimulation with the RT1.D $\mathrm{u} 320-44$ allopeptide. Data are presented as mean $\pm \operatorname{SEM}(n=5$ clones per group, 3 experiments).

tems). For each primer, different thermal cycling parameters were used as follows: denaturation at $94^{\circ} \mathrm{C}$ for 15 seconds, annealing temperature between $50^{\circ} \mathrm{C}$ and $60^{\circ} \mathrm{C}$ for 20 seconds, and extension for 1 minute (with a final extension of 7 minutes at the end of all cycles). PCR analysis was performed in duplicate on all cDNA samples. The amplification products were separated on $1 \%$ agarose gel $(16,22)$.

DTH response. We used an adoptive transfer system to study the functions of the Th cell clones in vivo, as previously described $(16,22)$. Responder LEW rats were injected intraperitoneally with the T-cell clones $\left(20 \times 10^{6}\right)$ and subsequently challenged 5 days later with a subcutaneous injection of $10 \mu \mathrm{g}$ of RT1.D $320-44$ or $10 \mu \mathrm{g}$ of RT1.D ${ }^{u} 320-44$ peptide in one ear and irradiated allogeneic WF spleen cells $\left(10 \times 10^{6}\right)$ in the other ear. In separate experiments, a mixture of the T-cell clones $\left(10 \times 10^{6}\right)$, $10 \mu \mathrm{g}$ of RT1.D ${ }^{\mathrm{u}} \beta 20-44$ allopeptide, and irradiated LEW APCs $\left(80 \times 10^{6}\right)$ were injected directly intradermally into the ear of naive LEW animals. A blinded observer measured DTH responses with a micrometer caliber (Mitutoyo, Aurora, Illinois, USA) 48 hours after challenge. Each measurement was performed at least four times and calculated mean was used as the final result. Results were calculated as $\Delta$ ear thickness before and after the challenge $\left(\times 10^{-2}\right.$ inches). Statistical analysis of data was assessed using the Student's $t$ test.

\section{Results}

Generation of RT1.D $\beta 20-44-$ specific T-cell lines. T-cell lines were established by repeated stimulation of graft-infiltrating cells from acutely rejecting and tolerant LEW recipients of WF renal allografts with the immunogenic RT1.D $320-44$ allopeptide presented by recipients' APCs. The cell lines were tested for reactivity to the RT1.D $320-44$ allopeptide and RT1.B ${ }^{\mathrm{u}} \beta 20-44$ control peptide in the presence of irradiated host APCs. After three stimulation cycles, the proliferative response of the lines was tested against the specific donor-derived and control allopeptides. The T-cell line generated from the tolerant graft had a significantly lower proliferative response to RT1.Duß20-44 allopeptide as compared with the $\mathrm{T}$-cell line from the rejected graft (Figure 1). The T-cell lines had no significant proliferation above base line after stimulation with the control RT1.B ${ }^{\mathrm{u}} \beta 20-44$ peptide.

Generation of T-cell clones. T-cell clones were then generated by limiting dilution from the T-cell lines after three stimulations using RT1.Duß20-44 peptide and fresh naive irradiated LEW APCs. Five T-cell clones from each T-cell line were generated and tested for their reactivity to the specific donor-derived and control class II MHC allopeptides. While all T-cell clones proliferated specifically to the RT1.D $320-44$ but not the control RT1.B ${ }^{\mathrm{u}} 320-44$ allopeptide, the proliferation of T-cell clones from the tolerant animal were significantly lower than those from the rejecting animal (Table 1), consistent with the $\mathrm{T}$ cell-line data above. No significant T-cell clone proliferation above base line was observed after stimulation with the control peptide RT1.B ${ }^{\mathrm{u}} 320-44$.

Phenotype of the T-cell lines and clones. The phenotypic characterization of the T-cell clones was determined by flow cytometry using anti-CD4 and anti-CD8 mAb's. All of the T-cell clones were found to express CD4 (Table 1). T-cell line and clone production of a panel of cytokines, including IL-2, IFN- $\gamma$, IL-4, IL-10, and the fibrogenic growth factor TGF- $\beta$, were tested by ELISA on culture supernatants after stimulation with the specific RT1.D ${ }^{\mathrm{u}} \beta 20-44$ or control RT1.B ${ }^{\mathrm{u}} \beta 20-44$ peptide. As seen in Figures 2 and 3, the T-cell line and clones from the rejecting graft produced IL- 2 and IFN- $\gamma($ Th1), whereas the T-cell line and clones from the tolerant graft produced IL-4 and IL-10 (Th2). TGF- $\beta$ was not

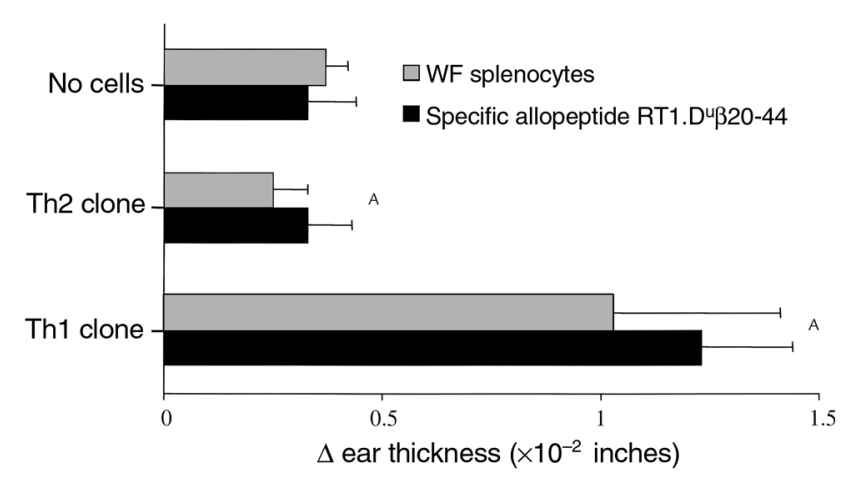

\section{Figure 4}

DTH responses in LEW rats were elicited after intraperitoneal injection of the Th 1 or Th 2 TCR V $\beta 9$ cell clones $\left(20 \times 10^{6}\right)$. Five days later, the animals were challenged by subcutaneous injection in the ear with RT1.Duß20-44 or whole-irradiated WF splenocytes. Changes in ear thickness were then measured 48 hours later. Bars represent the mean \pm SD $\Delta$ ear thickness (inches $\times 10^{-2}$ ). Naive LEW rats that are not injected with the clones or immunized with the allopeptides do not mount DTH responses ( $n=8$ animals/group, $\left.{ }^{A} P<0.0001\right)$. 

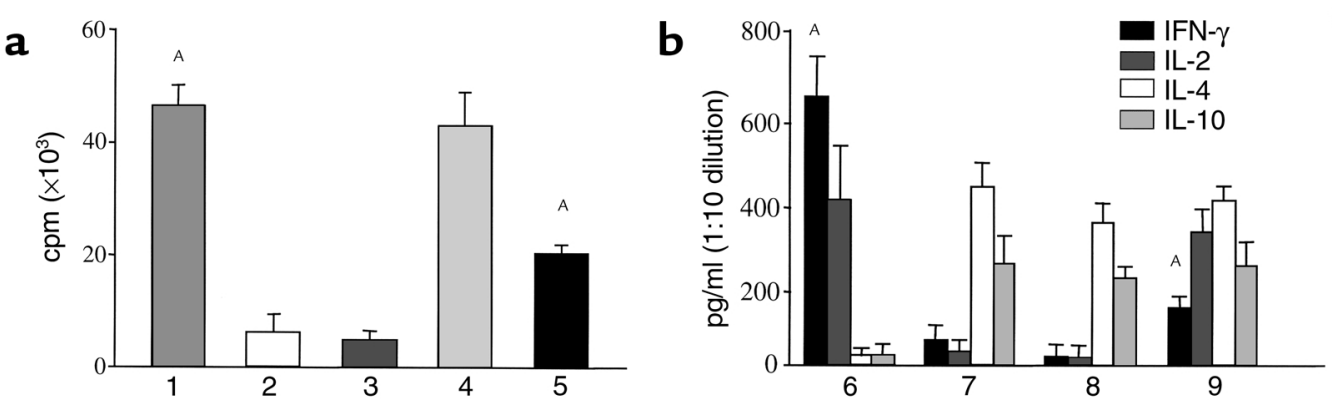

Figure 5

Regulatory function of Th2 clones in vitro. (a) Proliferation of TCR V $\beta 9$ Th1 clone from the rejecting animal, irradiated TCR V $\beta 9$ Th2 clone from the tolerant animal, and irradiated naive LEW T cells. 1, Th1 clone specific for RT1.Du $\beta 20-44+$ peptide RT1.D $320-44$. 2, irradiated naive LEW T cells + peptide RT1.Duß320-44. 3, irradiated Th2 clone specific for RT1.Duß320-44 + peptide RT1.Duß20-44. 4, Th1 clone specific for RT1.D ${ }^{u} \beta 20-44$ + irradiated naive LEW T cells + peptide RT1.D ${ }^{u} \beta 20-44$. 5, Th1 clone + irradiated Th2 clone both specific for RT1.Du $320-44$ + peptide RT1.Duß20-44. (b) Cytokine profile of TCR V 39 Th1 clone from the rejecting animal and irradiated TCR V 39 Th2 clone from the tolerant animal after restimulation with the RT1.D $320-44$ allopeptide. 6 , Th1 clone specific for RT1.D $320-44+$ peptide RT1.Du $\beta 20-44$. 7, Th2 clone specific for RT1.Du $320-44$ + peptide RT1.Du $320-44$. 8, irradiated Th2 clone specific for RT1.Du $320-44$ + peptide RT1.D ${ }^{u} \beta 20-44.9$, Th1 clone + irradiated Th2 clone both specific for RT1.Du $\beta 20-44$ + peptide RT1.Du $\beta 20-44$. Data are presented as mean $\pm \operatorname{SEM}\left(n=4,{ }^{A} P<0.0001\right)$.

detected in any of the culture supernatants tested. These findings indicate that at the clonal level, acute rejection in our model is associated with a Th1 phenotype, and tolerance is associated with a Th2 phenotype, thus confirming Sayegh's group's published data on intragraft cytokine expression patterns in vivo (7).

The TCR V $\beta$ gene usage of the T-cell clones was also examined. RT-PCR transcript analysis with specific rat TCR V $\beta$ primers (16) showed that the clones from both animal groups expressed a restricted TCR V $\beta$ repertoire. As shown in Table 1, the clones derived from each of the T-cell lines expressed different TCR V $\beta$ segments. Clones with TCR V $\beta 9$ were found to be expressed in both groups and were selected for further study. These data suggest that the TCR V $\beta$ segment per se does not determine the Th phenotype of an allospecific T-cell clone.

Functions of the allopeptide-specific T-cell clones in vivo. We have previously shown that self-restricted allopeptide (RT1.Duß20-44) specific Th1 clones transfer DTH responses in vivo $(16,22)$. The functions of alloreactive Th2-cell clones in vivo are unknown. Therefore, we tested the ability of the allopeptide specific TCR V $\beta 9$ expressing Th1 and Th2 clones to transfer antigen-specific DTH responses in vivo. Naive LEW animals were injected with the T-cell clones intraperitoneally and were subsequently challenged with either RT1.D ${ }^{\mathrm{u}} \beta 20-44$ allopeptide or irradiated allogeneic WF spleen cells. Naive animals do not normally mount DTH responses unless immunized with the allopeptide (17). Significant DTH responses were elicited after injection of the Th1 but not Th2 clones (Figure 4). In order to rule out the possibility that the lack of a DTH response observed with adoptive transfer of the Th2 cells was secondary to an inability of the cells to expand in vivo or migrate to the site of antigen (ears), we injected a mixture of the Th clones with the RT1.Duß320-44 allopeptide and irradiated APCs locally intradermally in the ears and measured
DTH responses. We obtained similar results with a $\Delta$ ear thickness of $0.45 \pm 0.054 \times 10^{-2}$ inches $(n=8)$ in animals injected with the Th1 cell clones and a zero $\Delta$ ear thickness $(n=8)$ in animals injected with the Th2 clones. These results confirm that the alloreactive $\mathrm{Th} 2$ clones do not induce antigen-specific DTH responses in vivo.

Regulatory function of Th2 clones in vitro. One of the potential functions of Th2 clones is to act as regulatory cells, thus inhibiting the function of Th1 cells. Such functions have been confirmed for autoreactive Th2 clones in autoimmune disease models $(11,23)$. However, there are no data on the regulatory functions of alloreactive Th2 clones. In order to study the putative regulatory functions of the Th2 clones in vitro, we set up a coculture system where irradiated cells ( $30 \mathrm{~Gy}$, to inhibit their proliferation) from the TCR V $\beta 9$ Th 2 clone or naive LEW T cells as control were cultured in a 1:1 ratio with cells from the TCR Vß9 Th1 clone along with irradiated (30 Gy) fresh LEW

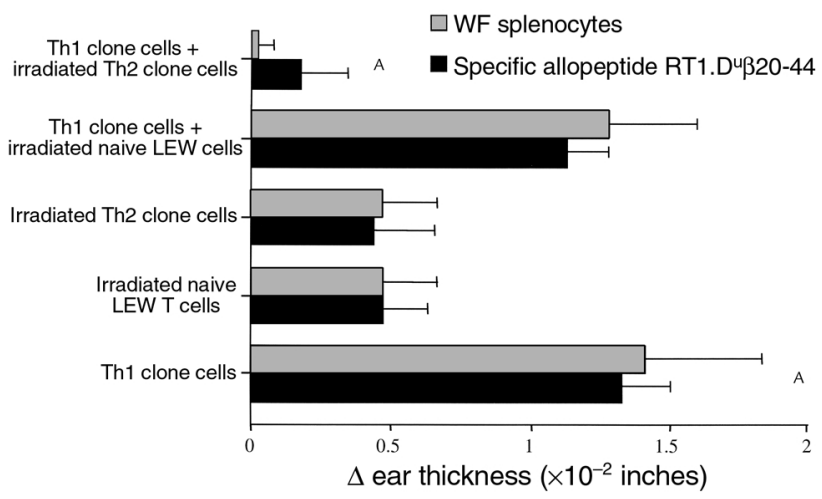

\section{Figure 6}

Regulatory function of the Th2 clones in vivo. The DTH response in LEW rats was elicited in animals injected with Th1 TCR V $\beta 9$, irradiated Th2 TCR V $\beta 9$ cell clones and irradiated naive LEW T cells in a 1:1 ratio. Bars represent the mean \pm SD $\Delta$ ear thickness (inches $\times 10^{-2}$, $n=8$ animals/group, $\left.{ }^{A} P<0.0001\right)$. 


\section{Figure 7}

T-cell line proliferation to specific donor-derived HLA-DR allopeptides in renal transplant recipients with chronic rejection (CR, two patients) and those with stable renal function (Stable, three patients). ${ }^{A} P \leq 0.001$ for proliferation in CR group versus Stable group (a). T-cell line cytokine profile patterns after restimulation with allopeptide between CR group and Stable group (b). No significant proliferation or cytokine production over base line was observed to the nonspecific (control) allopeptide for T-cell lines from either patient group. Data are presented as mean $\pm \operatorname{SEM}(n=3)$

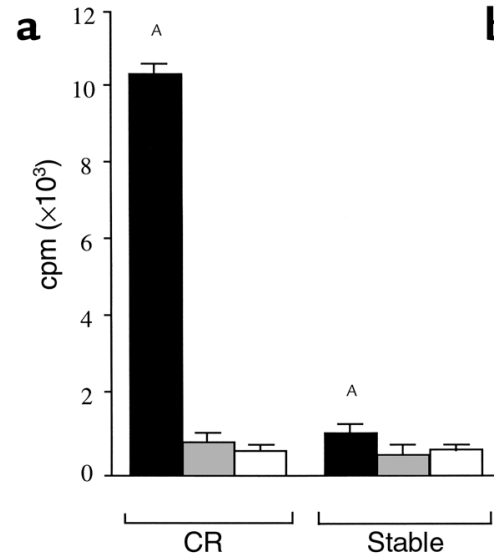

b

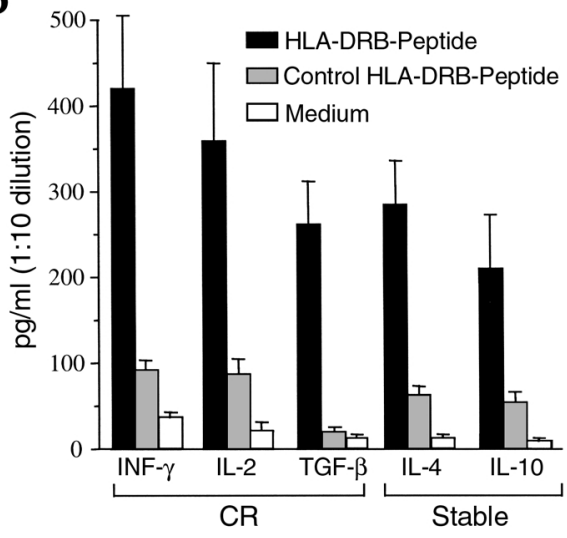

APCs plus allopeptide. Addition of the irradiated Th2 clone, but not of irradiated naive LEW T cells, significantly inhibited the proliferative response of the Th1 clone to the RT1.D ${ }^{u} 320-44$ allopeptide (Figure 5a). No significant proliferation was seen when the irradiated Th 2 clone specific for RT1.D ${ }^{u} 320-44$ or irradiated naive LEW T cells were cultured alone with the allopeptide.

Cytokine analysis by ELISA of the culture supernatants from the coculture experiment showed a 78.2\% reduction of IFN- $\gamma$ but not of IL- 2 production by the Th1 clone in the presence of the irradiated Th2 clone, but not in the presence of irradiated naive LEW T cells (not shown), in response to the RT1.D ${ }^{\mathrm{u}} \beta 20-44$ allopeptide (Figure $5 b$ ). IL-4 and IL-10 production were similar in all coculture supernatants. These data indicate that the allopeptide-specific Th2 clones can function as regulatory cells in vitro.

Regulatory function of Th2 clones in vivo. In order to study the regulatory function of Th2 clones in vivo, we injected intraperitoneally naive LEW animals with a mixture of the Th1 and irradiated Th2 clones or irradiated naive LEW T cells as controls and tested for DTH responses to the RT1.D $\mathrm{u} 320-44$ allopeptide and irradiated donor spleen cells. DTH responses to both the RT1.D ${ }^{\mathrm{u}} 320-44$ allopeptide and irradiated donor splenocytes were significantly reduced when Th1 clone cells were injected in combination with irradiated Th2 clone cells compared with animals injected with the Th1 clone alone (Figure 6). Injection of irradiated naive LEW $T$ cells had no effect on the generation of a DTH response by Th1 clone cells. These data indicate that self-restricted Th2 cells may function to regulate both direct and indirect Th1 alloimmune responses in vivo. Similarly, when irradiated Th2 cells were locally coinjected with Th1 cells intradermally into the ear (see above), DTH responses were significantly reduced $\left(\Delta\right.$ ear thickness: $0.1 \times 10^{-2}$ inches, $n=8, P=0.0001)$ as compared with Th1 clones alone $\left(0.45 \pm 0.054 \times 10^{-2}\right.$ inches, $n=8$ ).
T-cell lines and clones from renal transplant recipients. $\mathrm{T}$-cell lines and, subsequently, clones were generated by repeated stimulation of PBLs from three patients with stable graft function and two patients with chronic rejection with the mismatched donor-derived HLA-DR peptides presented by irradiated recipients' APCs. First, we tested the proliferative response of the T-cell lines and clones to the mismatched donor derived and irrelevant (control) HLA-DR peptides. $\mathrm{T}$-cell lines and clones generated from patients with chronic rejection had significantly higher proliferative responses as compared with those from patients with stable renal allograft function (Figure 7a). No significant proliferation above base line was seen after stimulation with the irrelevant HLA-DR control peptides in either patient group (Figure 7a).

Characterization of $M H C$ allopeptide specific $T$-cell lines and clones from buman renal transplant recipients. Further phenotypic characterization of the T-cell lines and clones was carried out by flow cytometric analysis using antiCD4 and anti-CD8 mAb's. All of the cell lines and clones expressed CD4 (Table 2). The TCR V $\beta$ gene usage of the T-cell clones was then examined using RT-PCR transcript analysis with the 24 specific human TCR V $\beta$ primers. Results indicated that the clones from both groups of patients expressed a restricted TCR V $\beta$ repertoire with a high degree of overlap (Table 2).

Cytokine analysis of the T-cell lines and clones using ELISA. We next examined the cytokine patterns of the donor HLA allopeptide-specific T-cell lines and clones from
Table 2

Characterization of HLA-DR allopeptide-reactive T-cell lines and clones from renal transplant recipients

$\begin{array}{lccccc}\begin{array}{l}\text { Cell line } \\ \text { CR }\end{array} & \text { Phenotype } & \text { HLA mismatch } & \text { Peptide } & \text { Cytokine } & \text { TCR-V } \beta \text { (clones) } \\ 1 & & & & & \\ 2 & \mathrm{CD}^{+} & \text {DR1 } & 42-62 & \text { IL-2, IFN- } \gamma & 5.2,8,9,13.1,13.1,13.2 \\ \text { Stable } & \mathrm{CD}^{+} & \text {DR3 } & 21-44 & \text { IL-2, IFN- } \gamma & 3,5.1,8,13.1,17 \\ 1 & & & & & \\ 2 & \mathrm{CD}^{+} & \text {DR1 } & 42-62 & \text { IL-4, IL-10 } & 5.1,5.2,6,8,9,13.1,13.1 \\ 3 & \mathrm{CD}^{+} & \text {DR2 } & 1-21 & \text { IL-4, IL-10 } & 4,6,6,13.1,13.1,13.1 \\ & \mathrm{CD}^{+} & \text {DR2 } & 41-60 & \text { IL-4, IL-10 } & 4,5.1,5.2,8,9,13.1,15\end{array}$

$\mathrm{CR}$, chronic rejection. 
stable and chronically rejecting patients. T-cell line and clone production of a panel of cytokines, including IFN- $\gamma$, IL-2, IL-4, and IL-10, and the fibrogenic growth factor TGF- $\beta$, was tested by ELISA on culture supernatants after stimulation with the specific HLA allopeptides. We found that the T-cell lines from patients with chronic graft dysfunction produced only the Th 1 cytokines IL- 2 and IFN- $\gamma$, after restimulation with peptide (Figure 7b). The T-cell lines generated from patients with stable graft function produced only the Th2 cytokines IL-4 and IL-10 (Figure $7 \mathrm{~b})$. Analysis of $31 \mathrm{~T}$-cell clones confirmed without exception this dichotomy; all 11 clones from the two chronically rejecting patients produced Th1 cytokines, while all 20 clones from the three stable patients produced Th2 cytokines in response to the specific donor HLA allopeptides.

\section{Discussion}

It is thought that acute allograft rejection is predominantly a Th1-mediated immune response. However, specific cytokine gene knockout mice show that allograft rejection can proceed in the absence of IL-2 (24) or IFN- $\gamma$ (25), indicating that not all Th1-associated cytokines are required for rejection to occur. Similar data have been recently reported for STAT4 gene knockout mice that are unable to mount normal Th1 responses (26). In some models, Th1 cytokines may also be required for tolerance induction $(25,27,28)$, possibly through the promotion of activation-induced cell death.

Th2 cytokines suppress cell-mediated immunity (6). Several studies in autoimmune disease and transplantation models show that tolerance induction, particularly by T-cell costimulatory blockade $(7,9,10,29)$, is associated with a state of immune deviation towards predominantly Th2 cell function with inhibition of Th1 and upregulation of Th2 cytokines in the target organ. Studies have been performed to examine the role of regulatory cells in tolerance induction $(30,31)$. The existence of regulatory cells in vitro through suppressor assays and in vivo by adoptive transfer of a state of infectious tolerance has been demonstrated $(31,32)$. However, these regulatory cells themselves have been difficult to clone and hence, to characterize. Recent data from Zhang et al. has identified a CD4-/CD8$\mathrm{T}$ cell that is capable of regulating antigen-specific $\mathrm{CD}^{+}$T-cell mediated Fas-dependent cell death (33). These cells, however, do not have a Th2-type cytokine profile and do not represent the mechanism of putative Th2-mediated T-cell regulation that has clearly been demonstrated in a number of studies $(30,34,35)$.

We have previously shown that class II MHC allopeptide-specific Th1 clones generated from animals rejecting renal allografts transferred specific DTH responses in vivo, indicating their important role in the pathogenesis of allograft rejection (16). In this study we generated $\mathrm{T}$-cell lines and clones from long-term surviving LEW recipients of WF kidney allografts and from acutely rejecting recipients against the immunodominant donor MHC peptide RT1.Du $320-44$ derived from the $\beta$-chain of the WF RT1.D (HLA-DR-like) to study the putative regulatory function of $\mathrm{Th} 2$ clones in vitro and in vivo. We showed that class II MHC allopeptide-specific T-cell clones generated from animals primed in vivo by immunization with the immunogenic class II MHC allopeptide RT1.D ${ }^{\mathrm{u}} \beta 20-44$ expressed TCR V $\beta 9$. T-cell clones generated from animals undergoing acute rejection also expressed TCR V $\beta 9$, and in addition, expressed two additional polymorphisms, TCR V $\beta 8.2$ and V $\beta 4$ (16). In this study, the T-cell clones from each line, i.e., from rejecting and tolerant animals, generally expressed different TCR V $\beta$ segments, and TCR V $\beta 9$ was found in both. This suggests that the physiologic processing of alloantigen leads to the presentation of additional epitopes, which get preferentially recognized by particular TCR V $\beta$ polymorphisms $(16,36)$. The fact that all of the $\mathrm{T}$-cell lines and clones are $\mathrm{CD}^{+}$is entirely consistent with the hypothesis that such cells encounter alloantigen in vivo in the context of self-MHC by the indirect pathway, and are thus class II MHC-restricted.

Here we demonstrated that the cytokine pattern, produced by the donor-specific peptide-primed T cells, is associated with the presence or absence of allograft dysfunction. Stable graft function is associated with a Th2 pattern of cytokines, whereas allograft dysfunction is associated with a Th1 pattern of cytokine production. There is evidence for a causative link between the T-cell cytokine production and the presence or absence of graft dysfunction. This is suggested by our findings that Th2 cytokine-producing T-cell clones suppressed the proliferative response and also the IFN- $\gamma$ production of the Th1 cytokine-producing clones, and inhibited DTH responses in vivo. These findings and published data from Sayegh's group $(7,37)$ and others (38) also argue against a link between a Th2 phenotype and development of chronic allograft dysfunction (39).

The results of this pilot study in renal transplant recipients provide evidence of a biological relevance for our rat studies to humans. Certainly, a prospective-type study where more patients are tested against a larger number of HLA-DR molecules is required in order to define the role and mechanisms of indirect allorecognition in chronic rejection and dissect the function of alloreactive Th1 and Th2 clones in humans.

In summary, in this study we provide the first description, to our knowledge, of the characteristics and function of Th1 and Th2 alloreactive T-cell clones generated via the indirect pathway of allorecognition. Our observations indicate that Th1 cells may play a pathogenic role in allograft rejection, whereas Th2 cells may provide a protective role by regulating Th1-cell clones in vivo.

\section{Acknowledgments}

This work was supported by NIH grants RO1 AI34965, AI 40629, and IZKF 01 KS 9603. Nader Najafian is supported by a National Kidney Foundation Fellowship Award. Anil Chandraker is supported by a National Kidney Foundation Young Investigator Award. 
1. Krensky, A., Weiss, A., Crabtree, G., Davis, M., and Parham, P. 1990. T-lymphocyte-antigen interactions in transplant rejection. N. Engl. J. Med. 322:510-517.

2. Sayegh, M.H., and Turka, L.A. 1998. The role of T cell costimulatory activation in transplant rejection. N. Engl. J. Med. 338:1813-1821.

3. Magee, C.C., and Sayegh, M.H. 1997. Peptide-mediated immunosuppression. Curr. Opin. Immunol. 9:669-675.

4. Krieger, N.R., DengPing, Y., and Fathman, C.G. 1996. CD4+ but not CD8+ cells are essential for allorecognition. J. Exp. Med. 184:2013-2018.

5. Mosmann, T.R., Cherwinski, H., Bond, M.W., Giedlin, M.A., and Coffman, R.L. 1986. Two types of murine helper T cell clone. I. Definition according to profiles of lymphokine activities and secreted proteins. $J$. Immunol. 136:2348-2357.

6. Paul, W.E., and Seder, R.A. 1994. Lymphocyte responses and cytokines. Cell. 76:241-251.

7. Sayegh, M.H., et al. 1995. CD28-B7 blockade after alloantigenic challenge in vivo inhibits Th1 cytokines but spares Th2. J. Exp. Med. 181:1869-1874.

8. Khoury, S.J., et al. 1995. Mechanisms of acquired thymic tolerance in experimental autoimmune encephalomyelitis: thymic dendritic-enriched cells induce specific peripheral $\mathrm{T}$ cell unresponsiveness in vivo. J. Exp. Med. 182:357-366.

9. Khoury, S.J., et al. 1996. Ex-vivo treatment of antigen presenting cells with CTLA4Ig and encephalitogenic peptide prevents experimental autoimmune encephalomyelitis in the Lewis rat. J. Immunol. 157:3700-3705.

10. Hancock, W.W., Sayegh, M.H., Peach, R., Linsley, P.S., and Turka, L.A 1996. Costimulatory function of CD40L, CD80 and CD86 in vascularized murine cardiac allograft rejection. Proc. Natl. Acad. Sci. USA. 93:13967-13972.

11. Kuchroo, V.K., et al. 1995. B7-1 and B7-2 costimulatory molecules differentially activate the Th1/Th2 developmental pathways: application to autoimmune disease therapy. Cell. 80:707-718.

12. Nickerson, P., et al. 1997. Manipulation of cytokine networks in transplantation: false hope or realistic opportunity for tolerance? Transplantation. 63:489-494.

13. Piccotti, J.R., Chan, S.Y., VanBuskirk, A.M., Eichwald, E.J., and Bishop, D.K. 1997. Are Th2 helper lymphocytes beneficial, deleterious, or irrelevant in promoting allograft survival? Transplantation. 63:619-624.

14. Field, E., Gao, Q., Chen, N., and Rouse, T. 1997. Balancing the immune system for tolerance: a case for regulatory CD4 cells. Transplantation. 64:1-7.

15. Lakkis, F., et al. 1997. Blocking the CD28-B7 T cell costimulation pathway induces long term cardiac allograft acceptance in the absence of IL4. J. Immunol. 158:2443-2448.

16. Waaga, A.M., et al. 1998. Mechanisms of indirect allorecognition: characterization of MHC class II allopeptide-specific T helper cell clones from animals undergoing acute allograft rejection. Transplantation. 65:876-883.

17. Sayegh, M.H., Khoury, S.K., Hancock, W.W., Weiner, H.L., and Carpenter, C.B. 1992. Induction of immunity and oral tolerance with polymorphic class II MHC allopeptides in the rat. Proc. Natl. Acad. Sci. USA. 89:7762-7766.

18. Watschinger, B., Gallon, L., Carpenter, C.B., and Sayegh, M.H. 1994. Mechanisms of allorecognition: recognition by in vivo primed T-cells of specific major histocompatibility complex polymorphisms presented as peptides by responder antigen-presenting cells. Transplantation. 57:572-577.

19. Gallon, L., et al. 1995. Indirect pathway of allorecognition: the occurrence of self-restricted $\mathrm{T}$ cell recognition of allo-MHC peptides early in acute allograft rejection and its inhibition by conventional immunosuppres- sion. Transplantation. 59:612-616

20. Vella, J.P., et al. 1999. Cellular and humoral mechanisms of vascularized allograft rejection induced by indirect recognition of donor $\mathrm{MHC}$ allopeptides. Transplantation. 67:1523-1532.

21. Vella, J.P., et al. 1997. Indirect allorecognition of major histocompatibility complex allopeptides in human renal transplant recipients with chronic graft dysfunction. Transplantation. 64:795-800.

22. Chen, W., et al. 1996. Mechanisms of indirect allorecognition in graft rejection: class II MHC allopeptide specific T cell clones transfer delayed type hypersensitivity responses in vivo. Transplantation. 62:705-710.

23. Chen, Y., Kuchroo, V.K., Inobe, J.-I., Hafler, D.A., and Weiner, H.L. 1994 Regulatory $\mathrm{T}$ cell clones induced by oral tolerance: suppression of autoimmune encephalomyelitis. Science. 265:1237-1240.

24. Steiger, J., Nickerson, P.W., Steurer, W., Moscovitch-Lopatin, M., and Strom, T.B. 1995. IL-2 knockout recipient mice reject islet cell allografts. J. Immunol. 155:489-498.

25. Konieczny, B.T., et al. 1998. IFN-gamma is critical for long-term allograft survival induced by blocking the CD28 and CD 40 ligand T cell costimulation pathways. J. Immunol. 160:2059-2064.

26. Kishimoto, K., et al. 2000. The role of CD154-CD40 versus CD28-B7 costimulatory pathways in regulating allogeneic Th1 and Th2 responses in vivo. J. Clin. Invest. 106:63-72

27. Dai, Z., Konieczny, B.T., Baddoura, F.K., and Lakkis, F.G. 1998. Impaired alloantigen-mediated $T$ cell apoptosis and failure to induce long-term allograft survival in IL-2-deficient mice. J. Immunol. 161:1659-1663.

28. Li, Y., Zheng, X.X., Li, X.C., Zand, M.S., and Strom, T.B. 1998. Combined costimulation blockade plus rapamycin but not cyclosporine produces permanent engraftment. Transplantation. 66:1387-1388.

29. Khoury, S.J., et al. 1995. CD28-B7 costimulatory blockade by CTLA4Ig prevents actively induced experimental autoimmune encephalomyelitis and inhibits Th1 but spares Th2 cytokines in the central nervous system. J. Immunol. 155:4521-4524.

30. Davies, J.D., et al. 1996. T cell regulation in adult transplantation tolerance. J. Immunol. 157:529-533.

31. Onodera, K., et al. 1996. Induction of infectious tolerance to MHCincompatible cardiac allografts in CD4 monoclonal antibody treated sensitized rat recipients. J. Immunol. 157:1944-1950.

32. Qin, S., et al. 1993. "Infectious" transplantation tolerance. Science. 259:974-976.

33. Zhang, Z.X., Yang, L., Young, K.J., DuTemple, B., and Zhang, L. 2000. Identification of a previously unknown antigen-specific regulatory $\mathrm{T}$ cell and its mechanism of suppression. Nat. Med. 6:782-789.

34. Onodera, K., et al. 1997. Type 2 helper T cell-type cytokines and the development of "infectious" tolerance in rat cardiac allograft recipients. $J$. Immunol. 158:1572-1581.

35. Dong, V.M., Womer, K.L., and Sayegh, M.H. 1999. Transplantation tolerance: the concept and its applicability. Pediatr. Transplant. 3:181-192.

36. Liu, Z., et al. 1993. Limited usage of $\mathrm{T}$ cell receptor $\mathrm{V}$ beta genes by allopeptide-specific T cells. J. Immunol. 150:3180-3186.

37. Azuma, H., et al. 1996. Blockade of T cell costimulation prevents development of experimental chronic allograft rejection. Proc. Natl. Acad. Sci. USA. 93:12439-12444

38. Hancock, W.W., Buelow, R., Sayegh, M.H., and Turka, L.A. 1998. Antibody-induced transplant arteriosclerosis is prevented by graft expression of anti-oxidant and anti-apoptotic genes. Nat. Med. 4:1392-1396.

39. Shirwan, H. 1999. Chronic allograft rejection. Do the Th2 cells preferentially induced by indirect alloantigen recognition play a dominant role? Transplantation. 68:715-726. 